\title{
Constraining the thermal history of an Archean craton: U-Pb thermochronology of lower crustal xenoliths from the Kaapvaal craton, southern Africa
}

Schmitz, M.D. ${ }^{1}$, Bowring, S.A. ${ }^{1}$, Robey, J.v.A. ${ }^{2}$

1. Department of Earth, Atmospheric, and Planetary Sciences, Massachusetts Institute of Technology, Cambridge, MA 02139, U.S.A.

2. Rockwise Consulting, 1 Lauder Street, Kimberley 8300 , South Africa

High precision TIMS U-Pb zircon geochronology and accessory phase thermochronology of mid- to lower crustal xenoliths erupted in Cretaceous kimberlites have been used to explore crustal structure and the thermal history of the Kaapvaal Craton of southern Africa. High-spatial resolution compositional data from back-scattered electron (BSE) and cathodoluminescence (CL) imaging are used to infer crystal growth histories and guide selective microsampling. Analysis of single grains and grain fragments have been used to unravel the complex thermal histories preserved within these xenoliths. Zircon, monazite, and rutile $\mathrm{U}-\mathrm{Pb}$ dates are interpreted in light of petrologic and petrographic data on accessory phase crystallization, dissolution and reprecipitation during metamorphic reactions, as well as the kinetics of diffusion and annealing of the various mineral lattices.

Xenoliths from the south-western margin of the Kaapvaal craton were examined to address questions regarding the age and structure of the suture between the Archean Kaapvaal and the bounding Proterozoic Namaqua-Natal mobile belt. Xenolith geochronology and thermochronology also provide information on the time-scales of decay of transient geotherms related to crustal growth and accretion, development of ambient continental geotherms, and the thermal state of the crust at the time of kimberlite entrainment. High-grade felsic gneiss and amphibolites from the Markt, Lovedale, and Klipfontein "Karoo" kimberlites have preliminary zircon protolith ages ca. 1.8 and 1.2 Ga, correlative with rocks from the craton-bounding Kheis and Namaqualand terrains. They also record complex metamorphic histories through zircon growth at ca. 1.1, 0.95 and $0.25 \mathrm{Ga}$. In contrast to these mid-crustal Proterozoic rocks, minute ovoid multifaceted zircons separated from an eclogite xenolith from the Lovedale kimberlite yield a discordia array most easily interpreted by crystallization of the zircons at $2.64 \mathrm{Ga}$ which were subsequently affected by recent $\mathrm{Pb}$ loss, perhaps during partial melting of the eclogite during kimberlite emplacement. These eclogitic zircons provide the first direct geochronological evidence of Archean lower crust in this portion of the craton.

Rutile in garnet granulites from the Markt and Lovedale kimberlites yield dates within error of the age of kimberlite emplacement. Considering the preservation of ancient $\mathrm{Pb}$ in rutile from other kimberlite-entrained xenoliths, we consider it unlikely that these data represent complete resetting of the mineral isotopic system during kimberlite magmatism. Rather these data are 
interpreted as recording an elevated crustal geotherm at the Kaapvaal margin relative to the interior "cratonic" geotherm during the Cretaceous.

Sapphirine granulite xenoliths from the central Kaapvaal (Lace \& Voorspoed kimberlites) contain abundant zircon, monazite, and rutile. In CL images, zircons exhibit complex "mosaic" zonation suggesting severe recrystallization; these zircons yield concordant dates at 2723 Ma. Monazites yield variably discordant data with ${ }^{207} \mathrm{~Pb} /{ }^{206} \mathrm{~Pb}$ dates from 2562 to $2723 \mathrm{Ma}$, and together form a linear array with approximate upper and lower intercepts of 2.72 and 1.2 Ga respectively. The zircon and monazite data are interpreted as recording ultra-high temperature metamorphism of the protoliths to the sapphirine granulites at $2.72 \mathrm{Ga}$.

Rutile in the sapphirine granulites contain zircon exsolution lamellae (Figures A \& B), only the second known occurrence of this phenomenon; this unique reaction provides two precise chronometers with which to explore the thermal evolution of the deep crust. Unlike interstitial zircon and monazite which record high-temperature metamorphism at $2.72 \mathrm{Ga}$, zircon lamellae mechanically separated from rutile yield variably discordant data forming an array with approximate upper and lower intercepts of $2.52 \mathrm{Ga}$ and $1.1 \mathrm{Ga}$ respectively. We interpret these data as recording the timing of unmixing of zircon from rutile. Also, clear visual evidence for growth and coarsening of the exsolution lamellae combined with the scatter in the exsolved zircon age data beyond analytical uncertainty may indicate a prolonged period of time during which this exsolution reaction took place (i.e. tens of millions of years). Further constraints on the thermodynamic and kinetic mechanisms of this exsolution reaction are needed before the significance of the zircon exsolution age can be fully assessed; knowledge of the temperature- and/or pressure-sensitivity of unmixing could lead to constraints on the cooling and/or uplift history of the craton.

The rutile grains hosting the exsolved zircon have also been analyzed; single rutile grains yield an array of discordant data with ${ }^{207} \mathrm{~Pb} /{ }^{206} \mathrm{~Pb}$ dates ranging from 1152 to $1906 \mathrm{Ma}$. Interpretation of this data requires distinguishing and quantifying the effects of: 1) mixing of radiogenic $\mathrm{Pb}$ in the rutile with $\mathrm{Pb}$ of Archean heritage locked in the exsolved zircon; 2) volume and short-circuit diffusional transport of $\mathrm{Pb}$ in the rutile lattice throughout the cooling history of the sample; and 3) possible recent Pb-loss during entrainment of the xenolith by the kimberlite and subsequent residence at the surface since the Late Cretaceous. The array of rutile ages clearly indicate prolonged open-system behaviour of $\mathrm{Pb}$ within the rutile. Further work to constrain the cooling history which produced the rutile age spectrum is underway. Specifically we hope to distinguish whether this mineral-isotopic system is preserving a record of slow cooling within the deep crust, or alternatively has been partially reset by a Proterozoic thermal event. Whichever process ultimately serves to explain the young rutile ages, the data indicate that the deep crust of the central Kaapvaal cooled through the closure temperature of rutile (nominally $400^{\circ} \mathrm{C}$ ) over 1 billion years ago. $\mathrm{U}-\mathrm{Pb}$ thermochronologic investigations of crustal xenoliths thus provide independent confirmation of thermal models for the lower crust of cratons and hold promise for mapping the thermal evolution of the continents in time and space. 


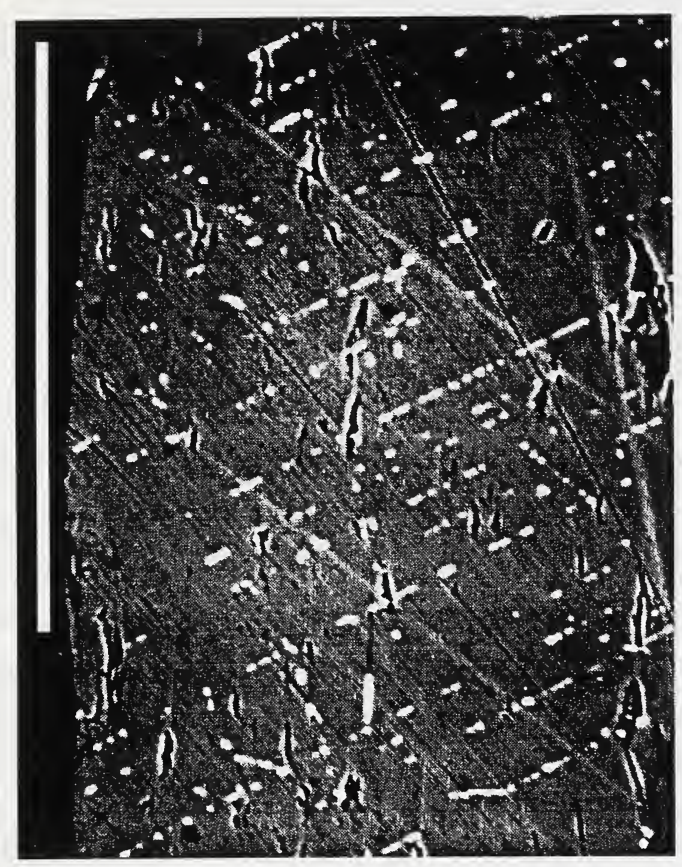

A

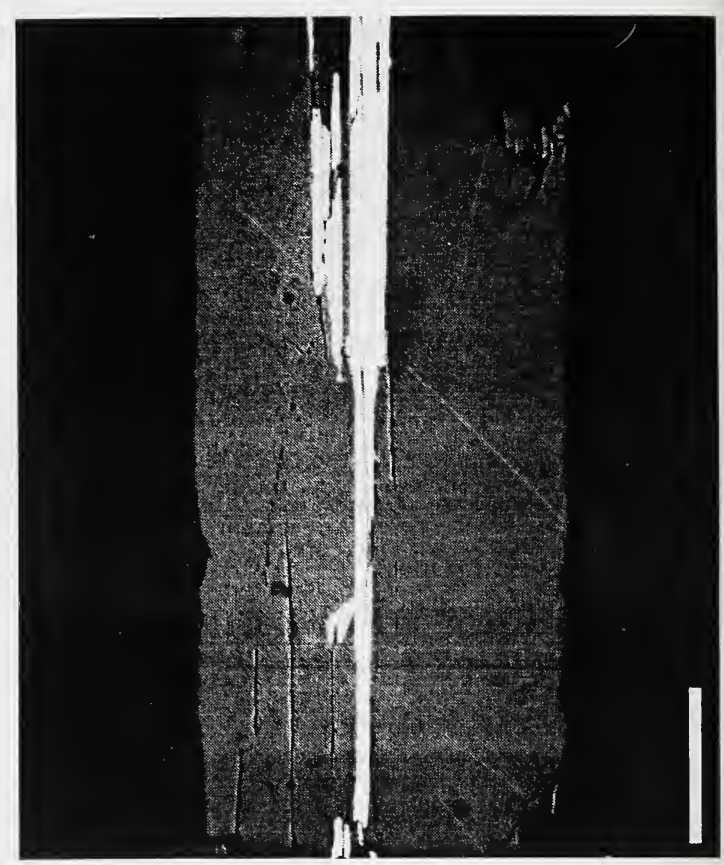

B

Figures A \& B: Two back-scattered electron images of zircon-rutile intergrowth phenomena in sapphirine granulite xenoliths from the Lace and Voorspoed kimberlites, which are interpreted as zircon exsolution from rutile. A: extremely fine needles of zircon (bright phase) are pervasive throughout the host rutile (dark phase), and oriented along three crystallographic planes. B: coarsened tablets of zircon within the center of a rutile grain which is otherwise clear of fine lamellae. Grains (not shown) with transitional morphologies between A and B are also observed, suggesting growth and coarsening of lamellae over the course of the unmixing. White scale bar in both images is $100 \mu \mathrm{m}$ in length. 